\title{
BMJ Open New index of social deprivation during pregnancy: results from a national study in France
}

\author{
Marion Opatowski, Béatrice Blondel, Babak Khoshnood, \\ Marie-Josèphe Saurel-Cubizolles
}

To cite: Opatowski M, Blondel B, Khoshnood B, et al. New index of social deprivation during pregnancy: results from a national study in France. BMJ Open 2016;6: e009511. doi:10.1136/ bmjopen-2015-009511

- Prepublication history for this paper is available online. To view these files please visit the journal online (http://dx.doi.org/10.1136/ bmjopen-2015-009511).

Received 24 July 2015 Revised 26 October 2015 Accepted 29 October 2015

CrossMark

INSERM UMR 1153Obstetrical, Perinatal and Pediatric Epidemiology Research Team (EPOPé), Center for Epidemiology and Statistics Sorbonne Paris Cité, DHU Risks in Pregnancy, Paris Descartes University, Paris, France

Correspondence to Dr Marie-Josèphe SaurelCubizolles; marie-josephe. saurel@inserm.fr

\section{ABSTRACT}

Objectives: To identify precariousness markers in pregnant women that differ from the usual socioeconomic variables.

Methods: Data were obtained from the National Perinatal Survey, a representative sample of women giving birth in France in 2010. From six indicators of social vulnerability, four were selected by multiple correspondence analysis. The first axis of this analysis was used, characterised by the following contributory variables: receiving RSA (Revenu de Solidarité Active) allowance; benefitting from the CMU (Couverture Maladie Universelle) system (French social security) or not being insured; not living in own accommodation; and not living with a partner. These four variables were summed to create a deprivation index.

Results: This index was strongly associated with social maternal characteristics and correctly identified women who were socially vulnerable. Furthermore, it was highly related to the psychosocial context, access to care, behaviours during pregnancy, and pregnancy outcomes. These associations remained significant after adjustment for social variables: compared with no deprivation (no factors), a high level of deprivation ( $\geq 3$ factors) was associated with late prenatal care (OR $5.8,95 \% \mathrm{Cl} 4.6$ to 7.2 ) and small for gestational age (OR $1.5,95 \% \mathrm{Cl} 1.1$ to 1.9 ).

Conclusions: This index of social deprivation was associated with health issues and behaviours during pregnancy, even after adjustment for social variables, revealing a dimension not measured by the usual variables. Moreover, it is simple to use and easily reproducible.

\section{INTRODUCTION}

Associations between social situation and health or access to care are well established. $^{1-7}$ Pregnancy is no exception, and associations have been described between social situation and medical complications during pregnancy or the neonatal period, especially preterm birth, growth retardation or infant mortality. ${ }^{8-14}$

In such studies, social situation is measured in different ways. It can be assessed with

\section{Strengths and limitations of this study}

- The main strength is the large and representative sample of births with a lot of social data allowing a deep analysis of social deprivation.

- The main limitation is the specificity of this index to France because it includes benefitfrom some social measures. Generalisation of this index will require adaptation of some of its components to the legislation of each country.

socioeconomic indicators such as income, educational level or occupational status, $^{2} \quad 3 \quad 8 \quad 10 \quad 11$ or sometimes with more complex scores aggregating several social characteristics. $^{1} \quad 9^{15-19}$ Thus, Townsend ${ }^{15}$ measured privation of a population with a territorial score, regrouping the following characteristics: rate of unemployment, overcrowded housing, not having a car, and not having personal accommodation. Borrell et $a l^{1}$ evaluated social deprivation using a socioeconomic index based on the features of an area: proportion of unemployment, manual workers, foreigners, and low education. Sass et $a l^{19}$ evaluated individual deprivation with 11 questions, such as meeting a social worker, not having social insurance, having financial difficulties, or amount of time spent on spare-time activities.

This multiplicity of indicators attests to the complexity of social vulnerability. In 1987, Wresinski $^{20}$ defined it as the lack of one or more securities enabling people to assume their elementary responsibilities and enjoy their fundamental rights. It can be more or less expansive and have more or less severe consequences. Deprivation can be measured at the geographical level, rather than individually. 11131516 In some studies, the socioeconomic situation of a residential area is used as proxy for individual deprivation. ${ }^{11} 21$ However, in health and especially for pregnant women, although residential area affects 
the individual, the social situation of the person has a major impact. $^{22-25}$

As mentioned above, in order to measure more precisely social vulnerability with its multidimensional aspects, some authors have developed social indexes. However, the existing scores are generally not suitable for pregnancy. Moreover, they are complex and difficult to use in situations other than data collection for surveys.

The aim of this study was to identify markers of deprivation for pregnant women that differ from the usual socioeconomic variables and show how they relate to medical care and pregnancy outcome. Aggregating these markers into a score will enable us to assess multidimensional social vulnerability and measure a deprivation gradient that is suitable for the period of pregnancy and easy to use in any situation.

\section{METHODS}

Data

A National Perinatal Survey of a nationally representative sample of births was performed in March 2010 (ENP 2010). Data collection covered all births in France during 1 week-that is, all liveborn or stillborn children, in public and private maternity units, as well as children born outside these facilities and then transferred to one, at a gestational age of least 22 weeks or with a weight at least $500 \mathrm{~g}$ at birth. ${ }^{26}$

Data were obtained from two sources: (1) an interview with mothers in the postpartum ward about their social and demographic characteristics and their behaviours during pregnancy and prenatal care; (2) medical records on complications during pregnancy or delivery and the child's health status at birth.

The National Council on Statistical Information (Comité du label) and the French Commission on Information Technology and Liberties (CNIL) approved this survey.

\section{Variables}

Social and demographic characteristics were collected by interviewing the women. Variables studied were age, nationality, educational level (<high school, high school, or graduate school), occupation of the woman and of her partner (number of jobs between the couple), household income and household allowances during pregnancy, social insurance at the beginning of the pregnancy, housing situation, and the mother forgoing healthcare because of financial reasons.

From these variables, six indicators of social deprivation during pregnancy were developed: (1) the household receiving unemployment allowance; (2) the household receiving the minimum resource allowance (Revenu de Solidarité Active (RSA)); (3) the woman having universal health insurance (Couverture Maladie Universelle (CMU)) or not insured; (4) the woman forgoing healthcare for financial reasons; (5) the woman not living in personal housing; (6) the woman not living with a partner.

Two variables used in the analysis refer to social benefits introduced in France to help deprived people: the RSA allowance and the CMU insurance. Since 2009, RSA (Solidarity Income) ensures a minimum income for people who have few resources. This allowance supplements the household's initial income to reach a guaranteed threshold. Since 2000, CMU (Universal Medical Insurance) has improved access to care with a generalisation of social security for people who do not benefit from it. So, if people are permanently residing in France, their medical costs are covered by social security under the same conditions as those who are insured.

Some variables describing behaviours during pregnancy, antenatal care and outcomes of the pregnancy were considered: (1) unwanted pregnancy; (2) late onset of prenatal care; (3) smoking tobacco during the third trimester; (4) preterm birth; (5) small for gestational age (SGA). Pregnancy was considered 'unwanted' when the mother declared that she would have preferred to be pregnant later or not be pregnant. The onset of prenatal care was considered 'late' when the pregnancy was declared after the first trimester. Indeed, declaration of the pregnancy is the first mandatory step in order to be well covered by social security. Preterm birth was defined as birth before 37 weeks of amenorrhoea, and SGA as birthweight under the 10th centile for gestational age and sex according to AUDIPOG curves. ${ }^{27}$

\section{Statistical analysis}

Correlation analysis was first performed with the six deprivation indicators and then multiple correspondence analysis (MCA). MCA is a 'data reduction' procedure. It analyses the pattern of relationships between categorical variables and summarises the information contained in the initial variables into factors that are easier to interpret. These factors are weighted linear combinations of the initial variables and are represented by axes that assemble variables present in similar individuals. ${ }^{18} 28$ The variables emerging from the first axis of MCA were combined into an index to measure social deprivation. The association between this new score and various socioeconomic variables was then explored to describe the characteristics of women in every class of the score.

Finally, associations between the score and variables describing behaviours, antenatal care and outcome of the pregnancy were analysed by logistic regression, with adjustment for age, nationality and educational level of the mother, and then with income.

Statistical analysis was performed using SAS V.9.3.

\section{RESULTS}

The sample included 14681 women living in metropolitan France. The analysis used data for 14326 women with a liveborn singleton; $4.1 \%$ of the records 
for these women were incomplete or empty, which was due to refusal, language barrier, or early discharge of the mother.

Overall, $14.0 \%$ of women benefitted from CMU or did not have any social insurance, $14.4 \%$ of women or their partner received unemployment insurance, and $10.3 \%$ received RSA; $7.3 \%$ of women reported that they did not live with a partner, and $7.2 \%$ did not live in personal housing; forgoing healthcare for financial reasons concerned $4.4 \%$ of the sample (table 1). Women who did not respond to any of these four questions were excluded (4.3\% of women); $1.8 \%$ of women had one, two or three missing answers. Missing data were coded as ' 0 '. Missing data was more common for women in poor social situations.

Correlations between these different indicators of deprivation were highly significant $(\mathrm{p}<0.001$, data not shown), except for two variables: unemployment allowance and forgoing healthcare. Despite strong associations, correlation coefficients between variables were low (from 0.27 to 0.52 ). All variables were retained for the rest of the analysis.

MCA was conducted with the six indicators, as shown in table 1 . The factorial analysis generated two principal axes with significant inertia (medium inertia was 0.16 ): the first one with inertia of 0.35 , and the second one with inertia of 0.17 . The first axis contrasted women with one or more of the following characteristics with women without these characteristics: benefitting from the CMU or without insurance, receiving RSA, not living in personal housing, and not living with a partner. It can be identified as a deprivation axis: the position of the woman on the axis reflects her degree of deprivation. The second axis was less easy to interpret. It put together the women receiving unemployment allowance and those forgoing care for financial reasons. These results were consistent with the correlation analysis.
The first axis, with four characteristics, was retained to create a score of deprivation, a gradual marker of social vulnerability. Contributory variables were combined into a pondered sum, with the weights provided by the MCA. The score was compared with a simple sum of the four characteristics: when an indicator was present, one point was added to the sum. The values of the simple sum ranged from 0 to 4 . The comparison, not presented here, showed an exact match between the two indices. Therefore, the non-pondered sum was retained.

The index value was 0 for $78.2 \%$ of the sample, 1 for $10.8 \%, 2$ for $6.2 \%$, and $\geq 3$ for $4.7 \%$. The score was strongly related to social and demographic variables (table 2). Compared with women with a zero score, women with a high score were more often young, under 25 years old, and foreign. They often had a low educational level and low household income and lived in jobless households. Therefore, these results confirmed that the index adequately identifies women in difficult social situations.

Associations between the score and some outcomes were tested (table 3). The higher the score, the higher the risk of unwanted pregnancy, late onset of prenatal care, and smoking during the third trimester. Even after adjustment for age, nationality and educational level, these associations remained highly significant. Checking collinearity showed that nationality and level of education are related, but they do not describe the same reality; each variable adds useful information, and, thanks to the large sample size, the quality of the models is good.

Finally, the deprivation index was associated with pregnancy outcomes: the score was associated with SGA, and, with score $\geq 1$, the risk of preterm birth was increased. After adjustment, the relation between these variables remained significant. The risk of preterm birth mainly increased for women with one deprivation indicator.

On adjustment for household income, the deprivation index remained strongly associated with prenatal care and

Table 1 Structure of the first two axes of the multiple correspondence analysis (MCA) conducted with the six indicators of social deprivation

\begin{tabular}{|c|c|c|c|c|}
\hline \multirow[b]{2}{*}{ Indicator } & \multirow[b]{2}{*}{ Category } & \multirow[b]{2}{*}{ n (\%) } & \multicolumn{2}{|c|}{ Weights of items * } \\
\hline & & & Factorial axis 1 & Factorial axis 2 \\
\hline \multirow[t]{2}{*}{ Social insurance } & Benefitting from $\mathrm{CMU}$ or without insurance & $1913(14.0)$ & 1.88 & 0.21 \\
\hline & Being insured & & -0.30 & -0.03 \\
\hline \multirow[t]{2}{*}{ RSA allowance } & Receiving RSA & $1395(10.3)$ & 2.28 & -0.12 \\
\hline & Not receiving RSA & & -0.26 & 0.01 \\
\hline \multirow[t]{2}{*}{ Personal housing } & Not living in personal housing & $981(7.2)$ & 2.33 & -0.54 \\
\hline & Living in personal housing & & -0.17 & 0.04 \\
\hline \multirow[t]{2}{*}{ Couple situation } & Not living with a partner & $998(7.3)$ & 2.52 & -0.60 \\
\hline & Living with a partner & & -0.19 & 0.04 \\
\hline \multirow[t]{2}{*}{ Forgoing medical care } & Forgoing & $603(4.4)$ & 1.17 & 2.57 \\
\hline & Not forgoing & & -0.05 & -0.12 \\
\hline \multirow[t]{2}{*}{ Unemployment allowance } & Receiving unemployment allowance & $1951(14.4)$ & 0.11 & 2.01 \\
\hline & Not receiving unemployment allowance & & -0.02 & -0.34 \\
\hline
\end{tabular}

*The item's weight corresponds to its coordinate on the axis. The contributing variables for each axis are in bold.

CMU, Universal Health Coverage (Couverture Maladie Universelle); RSA, Solidarity Income (Revenu de Solidarité Active). 
Table 2 Socioeconomic characteristics of the women by social deprivation index

\begin{tabular}{|c|c|c|c|c|c|}
\hline \multirow[b]{2}{*}{ Characteristic } & \multicolumn{4}{|c|}{ Deprivation index } & \multirow[b]{2}{*}{ p Value* } \\
\hline & 0 & 1 & 2 & $\geq 3$ & \\
\hline Percentage & 78.2 & 10.8 & 6.2 & 4.7 & \\
\hline Age (years) & & & & & $<0.001$ \\
\hline$<25$ & $1261(11.8)$ & $383(25.9)$ & $323(38.0)$ & $345(53.1)$ & \\
\hline $25-29$ & $3728(34.8)$ & 477 (32.2) & 237 (27.9) & $130(20.0)$ & \\
\hline $30-34$ & 3595 (33.5) & $365(24.7)$ & 165 (19.4) & 97 (14.9) & \\
\hline$>34$ & 2137 (19.9) & $254(17.2)$ & $124(14.6)$ & $78(12.0)$ & \\
\hline Nationality & & & & & $<0.001$ \\
\hline French & $9747(90.9)$ & $1090(73.7)$ & $611(71.7)$ & 476 (73.3) & \\
\hline Other European & $281(2.6)$ & $88(5.9)$ & $58(6.8)$ & $15(2.3)$ & \\
\hline African, Asian or other & $694(6.5)$ & $300(20.3)$ & $183(21.5)$ & $158(24.3)$ & \\
\hline Education & & & & & $<0.001$ \\
\hline$<$ High school & $2216(20.8)$ & $635(43.4)$ & $533(63.4)$ & $428(66.6)$ & \\
\hline High school & $1046(19.2)$ & $332(22.6)$ & $132(22.8)$ & $146(22.7)$ & \\
\hline Graduate school & $6403(60.0)$ & $500(34.1)$ & $116(13.8)$ & 69 (10.7) & \\
\hline Household income ( $€ /$ month) & & & & & $<0.001$ \\
\hline$<1000$ & $172(1.6)$ & $258(18.3)$ & $429(53.5)$ & $484(78.1)$ & \\
\hline 1000-1499 & $668(6.4)$ & $402(28.5)$ & $214(26.7)$ & $81(13.1)$ & \\
\hline 1500-1999 & 1485 (14.2) & 329 (23.3) & $110(13.7)$ & $36(5.8)$ & \\
\hline 2000-2999 & $3751(35.8)$ & $239(17.0)$ & $38(4.7)$ & $19(3.1)$ & \\
\hline$\geq 3000$ & $3751(42.0)$ & $181(12.8)$ & $11(1.4)$ & $0(0.0)$ & \\
\hline Jobs in the household & & & & & $<0.001$ \\
\hline No one is working & $211(2.0)$ & $246(16.7)$ & $377(45.0)$ & $412(64.1)$ & \\
\hline 1 job & $1529(23.6)$ & $687(46.8)$ & 363 (43.4) & $196(30.5)$ & \\
\hline 2 jobs & 7972 (74.3) & $536(36.5)$ & 97 (11.6) & $35(5.4)$ & \\
\hline Parity & & & & & $<0.001$ \\
\hline First delivery & $4675(43.7)$ & $621(42.1)$ & $347(41.0)$ & $308(47.7)$ & \\
\hline Second delivery & $3873(36.3)$ & $446(30.2)$ & $233(27.5)$ & $172(26.7)$ & \\
\hline Third delivery or more & $2133(20.0)$ & $408(27.7)$ & 266 (31.4) & 165 (25.6) & \\
\hline
\end{tabular}

behaviours during pregnancy. The association persisted for preterm birth but not for SGA (data not shown).

In comparison with other social variables, such as educational level, occupational status and household income, this index shows, as well or better, the differences in results (data not shown). For instance, concerning the level of education, $20 \%$ of the women without high school education did not want to be pregnant (instead of $35 \%$ of women with a high level of deprivation), $13 \%$ announced their pregnancy after the first trimester (instead of 31\%), 30\% smoked during pregnancy (instead of 34\%), $7 \%$ had a preterm birth (similar to $7.4 \%$ ), and $10.5 \%$ had a baby that was SGA (instead of $12.3 \%$ ).

\section{DISCUSSION}

Our statistical analysis brings out four indicators of social deprivation for pregnant women in France: (1) household receiving RSA allowance; (2) woman benefitting from the CMU or not having medical insurance; (3) woman not having personal housing; (4) woman not living with a partner during pregnancy.

These variables were combined into an index to measure deprivation, highlighting a social gradient. This approach has been used by others; some studies have developed a geographical index, ${ }^{1}{ }^{12} 131516$ sometimes used to address the lack of individual information. ${ }^{11} 21$ Other studies, less numerous, have resulted in indicators of individual poverty; they generally measure social disadvantage. ${ }^{9} 17-1929$ The most common method of creating an index is principal component analysis (PCA). ${ }^{12}{ }^{22}$ We prefer MCA. Indeed, MCA is suitable for qualitative variables, unlike PCA, which is designed for continuous variables with normal distribution. In addition, with PCA, variables with a greater number of subjects play a greater role in the analysis. MCA, through the $\chi^{2}$ distance, helps balance the weight of each modality. It is important because indicators of deprivation are poorly represented in the population. ${ }^{18} 192829$

This index is strongly related to the usual social characteristics: the greater the value of the index, the more difficult the social situation. In our study, women were often young ( $<25$ years old), foreign, poorly educated, with low income and in a jobless household. Some authors have also compared their poverty indexes with the usual social variables; ${ }^{919}$ their results describe strong links, which underscores the usefulness of summarising information as much as possible in a single indicator. 
Table 3 Association between deprivation index and characteristics of pregnancy

\begin{tabular}{|c|c|c|c|c|}
\hline \multirow[b]{2}{*}{ Pregnancy characteristic } & \multicolumn{4}{|c|}{ Deprivation index } \\
\hline & 0 & 1 & 2 & $\geq 3$ \\
\hline \multicolumn{5}{|l|}{ Unwanted pregnancy } \\
\hline$\%$ & 10.5 & 19.3 & 27.2 & 35.1 \\
\hline $\mathrm{aOR}^{*}$ & 1 & 1.73 & 2.36 & 3.19 \\
\hline $95 \% \mathrm{Cl}$ & & 1.49 to 2.01 & 1.98 to 2.82 & 2.64 to 3.86 \\
\hline$p$ Value & $<0.001$ & & & \\
\hline \multicolumn{5}{|l|}{ Late onset of prenatal care } \\
\hline$\%$ & 4.6 & 14.7 & 19.2 & 30.7 \\
\hline $\mathrm{aOR}^{*}$ & 1 & 2.65 & 3.26 & 5.79 \\
\hline $95 \% \mathrm{Cl}$ & & 2.20 to 3.18 & 2.63 to 4.04 & 4.65 to 7.20 \\
\hline$p$ Value & $<0.001$ & & & \\
\hline \multicolumn{5}{|l|}{ Smoking during pregnancy } \\
\hline$\%$ & 14.8 & 20.4 & 30.2 & 33.9 \\
\hline $\mathrm{aOR}^{*}$ & 1 & 1.30 & 1.81 & 2.11 \\
\hline $95 \% \mathrm{Cl}$ & & 1.12 to 1.51 & 1.52 to 2.16 & 1.73 to 2.57 \\
\hline$p$ Value & $<0.001$ & & & \\
\hline \multicolumn{5}{|l|}{ Small for gestational age } \\
\hline$\%$ & 7.7 & 10.0 & 11.6 & 12.3 \\
\hline $\mathrm{aOR}^{*}$ & 1 & 1.31 & 1.43 & 1.49 \\
\hline $95 \% \mathrm{Cl}$ & & 1.08 to 1.58 & 1.13 to 1.82 & 1.14 to 1.94 \\
\hline$p$ Value & $<0.001$ & & & \\
\hline \multicolumn{5}{|l|}{ Preterm birth } \\
\hline$\%$ & 4.7 & 7.4 & 7.6 & 7.4 \\
\hline $\mathrm{aOR}^{*}$ & 1 & 1.42 & 1.33 & 1.25 \\
\hline $95 \% \mathrm{Cl}$ & & 1.14 to 1.78 & 1.00 to 1.78 & 0.90 to 1.74 \\
\hline$p$ Value & $<0.001$ & & & \\
\hline
\end{tabular}

Consistent with other studies, our results show that the social situation as described by the index is related to the desire for pregnancy, ${ }^{9}{ }^{10}$ prenatal care, ${ }^{2}{ }^{30}$ smoking during pregnancy, ${ }^{10}$ and SGA infants. ${ }^{15}{ }^{26}$ The link with preterm birth is less clear despite an excess of risk as soon as the index is higher than 0 , even after adjustment for the usual social variables. ${ }^{13}{ }^{15}$ So, the association between the index and the pregnancy variables is not totally explained by the usual social indicators. The deprivation index probably contains a dimension not measured by the other social variables. This idea is supported by the index showing bigger differences between women than other variables, especially concerning psychological status, behaviours, and access to care. These domains are very important during the pregnancy period.

One limitation of this index is its specificity to France: two of the variables selected correspond to receiving social benefits, the RSA and CMU. More than 2 million households in France benefitted from the RSA in 2014, which is an increase of $6 \%$ since $2013,{ }^{31}$ and 2.3 million people benefitted from the CMU system at the end of 2013. ${ }^{32}$ These social benefits help the poorest families. They act as both protection and deprivation marker.

Some women were not included in the survey because of their refusal or their inability to be interviewed-for instance, women who did not speak French. Likewise, mothers of stillborn babies were excluded. It is likely that these women were more deprived than in our sample. Moreover, non-recourse to social benefits-RSA or CMU-is still common, affecting $35-68 \%$ of people eligible for RSA in $2011 .^{33}$ Using these variables as a component of the index means that this population is not taken into account, and deprivation in the sample is underestimated. However, in the specific context of pregnancy, women access social benefits to which they are entitled more often than does the general population. Finally, missing data, not shown here, represent about $5 \%$ of the sample for the variables of interest. They are more common among women in poor social situations. This finding may lead to bias with a slight underestimation of deprivation. Nevertheless, the link between the deprivation index and health variables, which is probably reduced by the underestimation of deprivation, is still significant.

The main strength of this study is the large size of the national sample, which allowed good representation of the poorest women, and the good quality of the sample, with its representativeness at the national level. In this study, the use of a deprivation index was preferred for describing the social situation of the new mothers. The complexity of the concept of deprivation means that several situations and factors need to be taken into account in the analysis. Thus, from simple dichotomous 
variables, the index addresses different dimensions, such as financial resources, cohabitation, housing, and access to medical care. This index is easily reproducible, and the variables that compose it can be easily used with low risk of incorrect answers. Its use helps to address the lack of objective definitions of deprivation in obstetrics; it may be useful for practitioners for different stages of pregnancy to identify the poorest women and direct them to social workers and the services to which they are entitled.

Acknowledgements The authors thank the Maternal and Child Health Service in each district, the heads of the maternity units, the investigators, and all of the women who participated in the survey.

Contributors MO and M-JS-C were the main contributors to the analysis of data and initially drafted the manuscript. BK gave statistical advice. BB was responsible for data collection. All authors were involved in critical revision of the intellectual content. All authors approved the final manuscript.

Funding The 2010 National Perinatal Survey and this study were funded by the Directorate General of Health (DGS) and the Directorate of Research, Studies, Evaluation, and Statistics (DREES) of the National Department of Health. INSERM Unit 953 received a grant from the Bettencourt Foundation (Coups d'élan pour la Recherche Francaise) to support its research activities.

Competing interests None declared.

Ethics approval The National Council on Statistical Information (Comité du label) and the French Commission on Information Technology and Liberties (CNIL) approved this survey.

Provenance and peer review Not commissioned; externally peer reviewed.

Data sharing statement No additional data are available.

Open Access This is an Open Access article distributed in accordance with the Creative Commons Attribution Non Commercial (CC BY-NC 4.0) license, which permits others to distribute, remix, adapt, build upon this work noncommercially, and license their derivative works on different terms, provided the original work is properly cited and the use is non-commercial. See: http:// creativecommons.org/licenses/by-nc/4.0/

\section{REFERENCES}

1. Borrell C, Marí-Dell'olmo M, Palència L, et al. Socioeconomic inequalities in mortality in 16 European cities. Scand J Public Health 2014;42:245-54.

2. Chiavarini M, Lanari D, Minelli L, et al. Socio-demographic determinants and access to prenatal care in Italy. BMC Health Serv Res 2014;14:174.

3. Leclerc A, Chastang JF, Menvielle G, et al. Socioeconomic inequalities in premature mortality in France: have they widened in recent decades? Soc Sci Med 2006;62:2035-45.

4. Leclerc A, Kaminski M, Lang T. Inégaux face à la santé-Du constat à l'action. Paris: Inserm-La Découverte, 2008.

5. Siddiqi AA, Wang S, Quinn K, et al. Racial disparities in access to care under conditions of universal coverage. Am J Prev Med 2016;50:220-5

6. Moisy M. Etat de santé et renoncement aux soins des bénéficiaires du RSA. Etudes Résultats 2014:882.

7. Karimi M, Geoffroy-Perez B, Fouquet A, et al. Socioprofessional trajectories and mortality in France, 1976-2002: a longitudinal follow-up of administrative data. J Epidemiol Community Health 2015;69:339-46.

8. Luque-Fernandez MA, Franco M, Gelaye B, et al. Unemployment and stillbirth risk among foreign-born and Spanish pregnant women in Spain, 2007-2010: a multilevel analysis study. Eur J Epidemiol 2013;28:991-9.

9. Gayral-Taminh M, Daubisse-Marliac L, Baron M, et al. Caractéristiques socio-démographiques et risques périnatals des mères en situation de précarité. J Gynécologie Obstétrique Biol Reprod 2008;34:23-32.

10. Larrañaga I, Santa-Marina L, Begiristain $\mathrm{H}$, et al. Socio-economic inequalities in health, habits and self-care during pregnancy in Spain. Matern Child Health J 2012;17:1315-24.

11. Bonet M, Smith LK, Pilkington $\mathrm{H}$, et al. Neighbourhood deprivation and very preterm birth in an English and French cohort. BMC Pregnancy Childbirth 2013;13:97.

12. Singh GK, Kogan MD. Persistent socioeconomic disparities in infant, neonatal, and postneonatal mortality rates in the United States, 1969-2001. Pediatrics 2007;119:e928-39.

13. Poeran J, Maas AFG, Birnie E, et al. Social deprivation and adverse perinatal outcomes among Western and non-Western pregnant women in a Dutch urban population. Soc Sci Med 1982 2013:83:42-9.

14. Kaminski M, Blondel B, Saurel-Cubizolles M-J. La santé périnatale. In: Leclerc A, Fassin D, Grandjean $\mathrm{H}$, et al, eds. Les inégalités sociales de santé. Paris: Inserm- La Découverte, 2000:173-92.

15. Townsend P. Deprivation. J Soc Policy 1987;16:125-46.

16. Carstairs V, Morris R. Deprivation: explaining differences in mortality between Scotland and England and Wales. BMJ 1989;299:886-9.

17. Salmond C, Crampton $P$, King $P$, et al. NZiDep: a New Zealand index of socioeconomic deprivation for individuals. Soc Sci Med 2006;62:1474-85.

18. Frikkie Booysen $S$ van der B. Using an asset index to assess trends in poverty in seven sub-saharan african countries. World Dev 2008;36:1113-30.

19. Sass C, Moulin J-J, Guéguen R, et al. Le score Epices : un score individuel de précarité. Construction du score et mesure des relations avec des données de santé, dans une population de 197 389 personnes. Bulletin Epidémiologique Hebdomadaire 2006;14:93-6.

20. Wresinski J. Grande pauvreté et précarité économique et sociale. Journal Officiel 1987;6.

21. Pornet C, Delpierre C, Dejardin O, et al. Construction of an adaptable European transnational ecological deprivation index: the French version. J Epidemiol Community Health 2012;66:982-9.

22. Pampalon R, Hamel D, Gamache P. Health inequalities in urban and rural Canada: comparing inequalities in survival according to an individual and area-based deprivation index. Health Place 2010;16:416-20.

23. Steenland K, Henley J, Calle E, et al. Individual- and area-level socioeconomic status variables as predictors of mortality in a cohort of 179,383 persons. Am J Epidemiol 2004;159:1047-56.

24. Chiavarini $M$, Bartolucci $F$, Gili $A$, et al. Effects of individual and social factors on preterm birth and low birth weight: empirical evidence from regional data in Italy. Int $J$ Public Health 2012:57:261-8.

25. Pardo-Crespo MR, Narla NP, Williams AR, et al. Comparison of individual-level versus area-level socioeconomic measures in assessing health outcomes of children in Olmsted County, Minnesota. J Epidemiol Community Health 2013;67:305-10.

26. Blondel $\mathrm{B}$, Lelong $\mathrm{N}$, Kermarrec $\mathrm{M}$, et al. Trends in perinatal health in France from 1995 to 2010 . Results from the French National Perinatal Surveys. J Gynécologie Obstétrique Biol Reprod 2012;41: e1-15.

27. Vendittelli F, Rivière $O$, Pinquier D, et al. Intérêt d'une base de données périnatales: mise à jour des courbes de morphométrie néonatale française. Rev Epidémiol Sante Publique 2008;56:322.

28. Asselin L M, Tyan Anh V. Multidimensional poverty and multiple correspondence analysis. In: Kakwani N, Silber J, eds. Quantitative approaches to multidimensional poverty measurement. Palgrave Macmillan, 2008:80-103.

29. Wabiri N, Taffa N. Socio-economic inequality and HIV in South Africa. BMC Public Health 2013;13:1037.

30. Brugier C, Morel O, Ricbourg A, et al. Impact de la précarité sur la qualité du dépistage anténatal: expérience de l'hôpital Lariboisière à Paris. J Gynécologie Obstétrique Biol Reprod 2012:41:454-9.

31. Les foyers bénéficiaires du RSA fin juin 2014. RSA Conjoncture $2014 ; 7$.

32. Fonds CMU. Rapport d'activité 2013. Fonds de financement de la protection complémentaire de la couverture universelle du risque maladie, 2014

33. Le rapport de l'Observatoire national de la pauvreté et de l'exclusion 2010-2011-Crise économique, marché du travail et pauvreté. ONPE 2012 